\title{
Determining the optimal surveillance interval after a colonoscopic polypectomy for the Korean population?
}

\author{
Jung Lok Lee ${ }^{1}$, Jae Myung Cha ${ }^{1}$, Hye Min Lee ${ }^{1}$, Jung Won Jeon ${ }^{1}$, Min Seob Kwak ${ }^{1}$, Jin Young Yoon ${ }^{1}$, \\ Hyun Phil Shin ${ }^{1}$, Kwang Ro Joo ${ }^{1}$, Joung Il Lee ${ }^{1}$, Dong Il Park ${ }^{2}$ \\ ${ }^{1}$ Department of Internal Medicine, Kyung Hee University School of Medicine, Seoul, ${ }^{2}$ Department of Internal Medicine, Sungkyunkwan \\ University School of Medicine, Seoul, Korea
}

Background/Aims: Western surveillance strategies cannot be directly adapted to the Korean population. The aim of this study was to estimate the risk of metachronous neoplasia and the optimal surveillance interval in the Korean population. Methods: Clinical and pathological data from index colonoscopy performed between June 2006 and July 2008 and who had surveillance colonoscopies up to May 2015 were compared between low- and high-risk adenoma (LRA and HRA) groups. The 3- and 5-year cumulative risk of metachronous colorectal neoplasia in both groups were compared. Results: Among 895 eligible patients, surveillance colonoscopy was performed in 399 (44.6\%). Most (83.3\%) patients with LRA had a surveillance colonoscopy within 5 years and $70.2 \%$ of patients with HRA had a surveillance colonoscopy within 3 years. The cumulative risk of metachronous advanced adenoma was $3.2 \%$ within 5 years in the LRA group and only $1.7 \%$ within 3 years in the HRA group. The risk of metachronous neoplasia was similar between the surveillance interval of $<5$ and $\geq 5$ years in the LRA group; however, it was slightly higher at surveillance interval of $\geq 3$ than $<3$ years in the HRA group ( $9.4 \%$ vs. $2.4 \%$ ). In multivariate analysis, age and the $\geq 3$-year surveillance interval were significant independent risk factors for metachronous advanced adenoma $(P=0.024$ and $P=0.030$, respectively). Conclusions: Patients had a surveillance colonoscopy before the recommended guidelines despite a low risk of metachronous neoplasia. However, the risk of metachronous advanced adenoma was increased in elderly patients and those with a $\geq 3$-year surveillance interval. (Intest Res 2017;15:109-117)

Key Words: Colorectal neoplasms; Surveillance; Guideline; Colonoscopy; Polypectomy

\section{INTRODUCTION}

Colorectal cancer (CRC) screening and colonoscopic polypectomy are generally considered to be the most effective methods for CRC prevention. ${ }^{1-3}$ Patients with colorectal neoplasias are known to be at an increased risk for developing metachronous neoplasias compared with patients without neoplasias. As surveillance colonoscopy can detect metachronous neoplasias, ${ }^{4}$ surveillance intervals are based

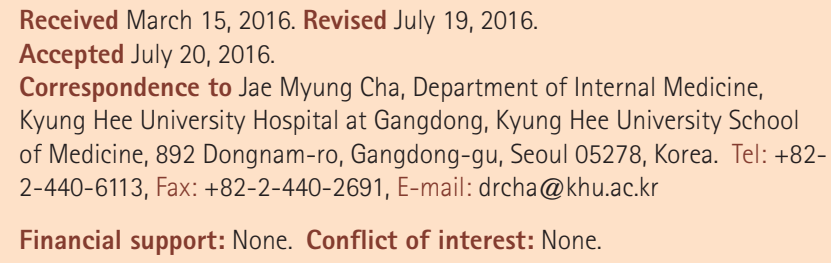

Financial support: None. Conflict of interest: None.

on the concept of risk stratification of baseline colonoscopy findings. ${ }^{4-6}$ The United States Multi-Society Task Force (USMSTF) on CRC issued guidelines for post-polypectomy surveillance. ${ }^{4}$ The USMSTF recommended surveillance intervals based on two major risk groups at baseline colonoscopy: a 5-year interval for low-risk adenoma (LRA), defined as one to two tubular adenomas $<10 \mathrm{~mm}$, and a 3 -year interval for high-risk adenoma (HRA), defined as adenoma with villous histology, $\geq 10 \mathrm{~mm}$, high-grade dysplasia (HGD), or three or more adenomas. ${ }^{4}$ The British Society of Gastroenterology recommended surveillance intervals based on three major risk groups at baseline colonoscopy: (1) a 5-year interval for LRA, defined as one to two adenomas $<10 \mathrm{~mm}$; (2) a 3 -year interval for intermediate risk, defined as three to four small adenomas or one $\geq 10 \mathrm{~mm}$; and (3) a 1-year interval for

\footnotetext{
๑ Copyright 2017. Korean Association for the Study of Intestinal Diseases. All rights reserved.

This is an Open Access article distributed under the terms of the Creative Commons Attribution Non-Commercial License (http://creativecommons.org/licenses/by-nc/4.0)

which permits unrestricted non-commercial use, distribution, and reproduction in any medium, provided the original work is properly cited.
} 
HRA, defined as five small adenomas or three or more with at least one $\geq 10 \mathrm{~mm}^{5}{ }^{5}$ The Korean Society of Gastroenterology similarly recommended surveillance intervals based on two major risk groups at baseline colonoscopy: (1) a 5-year interval for LRA and (2) a 3-year interval for HRA, defined as an adenoma with villous histology, HGD, an adenoma $\geq 10 \mathrm{~mm}$, three or more adenomas, or serrated polyps $\geq 10 \mathrm{~mm}^{6}{ }^{6}$

However, until now, few studies have been conducted to validate the risk stratification surveillance in the Korean population. ${ }^{7}$ As the risk and characteristics of colorectal neoplasia may be different between Western and Asian populations, ${ }^{8}$ Western surveillance strategies cannot be directly adapted to the Korean population. In addition, many Western colonoscopists have recommended earlier surveillance colonoscopies than the guidelines. ${ }^{9-11}$ Therefore, the risk of metachronous neoplasia and the optimal surveillance interval need to be evaluated in the Korean population.

The aim of this study was to estimate the risk of metachronous neoplasia and optimal surveillance interval in the Korean population.

\section{METHODS}

\section{Subjects}

This is a retrospective cohort study of 895 patients who underwent complete colonoscopic polypectomies between June 1, 2006, and July 31, 2008, at the Kyung Hee University Hospital at Gangdong, Seoul, Korea. After index colonoscopy, patients who underwent one or more surveillance colonoscopies up to May 31, 2015, were eligible for this study. The cumulative risk of metachronous adenoma and advanced adenoma of the LRA and HRA groups were compared at surveillance colonoscopy. Furthermore, the potential risk factors for metachronous advanced adenoma were evaluated. Subjects were excluded if they had (1) CRC, IBD, polyposis syndrome, or hereditary non-polyposis CRC; (2) an incomplete colonoscopy due to inadequate preparation or cecal intubation failure; or (3) surgical resection of the colon or rectum at index colonoscopies. Subjects were also excluded if they had only diminutive polyps removed without polypectomy or no polyps. The surveillance colonoscopy interval after index colonoscopy was based on the Korean and USMSTF guidelines: ${ }^{4,6}$ a 5-year interval for LRA and a 3-year interval for HRA. Each patient was informed of their scheduled surveillance interval; however, the actual time of surveillance colonoscopy was left to the physician's discretion and patients' preference, without a rigid protocol.
A "complete colonoscopic polypectomy" at index colonoscopy was defined as the following: colonoscope insertion into the cecum, adequate preparation, polypectomy of all detected polyps, and the endoscopist's attestation of complete polyp removal through careful macroscopic inspection of the resection margins. In our hospital, narrow-band imaging or chromoendoscopy is used to define a macroscopically clear resection margin after polypectomy and argon plasma coagulation is used to eradicate potential remnants at the polypectomy sites. However, these applications were not routinely used and are often used at the discretion of the attending endoscopists. In the case of a repeated colonoscopy within 6 months to complete the prior colonoscopy due to a remnant polyp or to check the completeness of the prior polypectomy, the results were judged to be a part of the prior colonoscopy findings, i.e., additional adenomas were classified as missed lesions and included as a part of the prior colonoscopy findings. A metachronous neoplasia was defined as a neoplasia found during surveillance colonoscopy performed at least 6 months after the index colonoscopy. The findings from each subject were stratified according to the most advanced lesion detected.

At index colonoscopy, the patients' height and body weight were measured and they were questioned by a study coordinator about their tobacco and aspirin/NSAID use and family history of CRC in their first-degree relatives. A patient was defined as a current smoker if they consumed at least one pack per week. Regular aspirin/NSAID use was defined as having taken aspirin/NSAIDs for more than 12 months. This study was approved by the Institutional Review Board of the Kyung Hee University Hospital at Gangdong (KHNMC IRB-2015-07-053).

\section{Colonoscopy and Pathology}

All colonoscopic procedures were performed by seven board-certified attending gastroenterologists who were highly experienced, with an adenoma detection rate $\geq 25 \%$ and having performed 5,000 to 20,000 colonoscopies. Conventional white light colonoscopes (CF-H260 series, Olympus, Aizu, Japan; EC-450HL5, EC-450WM5, or EC-590ZW, Fujinon Inc., Saitama, Japan) were used for all procedures. Most colonoscopies were performed under conscious sedation with a polyethylene glycol-based split regimen. Preparation quality was assessed using the Boston bowel preparation scale ${ }^{12,13}$ with a score $\geq 5$ points considered as adequate preparation. ${ }^{13}$ All detected polyps were completely removed with the intention of en bloc resection using the blended 
coagulation mode of the available electrocautery equipment (Erbe USA Inc., Marietta, GA, USA).

All polyps were documented for their number, location, shape, and size. All removed polyps were sent for histopathologic examination and were classified by expert pathologists according to World Health Organization criteria. ${ }^{14}$ LRA was defined as one to two tubular adenomas $<10 \mathrm{~mm}$ and HRA was defined as advanced adenoma, $\geq 10 \mathrm{~mm}$ in diameter, containing $>25 \%$ villous structure or HGD, or three or more adenomas. ${ }^{4,6}$ Pathological interpretation of an intramucosal carcinoma or carcinoma in situ was classified as an HGD ${ }^{14}$ The proximal colon was defined as all areas proximal to the splenic flexure.

\section{Statistical Analysis}

The primary endpoint was a cumulative incidence of metachronous advanced adenoma on surveillance colonoscopy according to risk stratification group at index colonoscopy. Secondary endpoints included the 3- or 5-year cumulative risk of metachronous adenoma and advanced adenoma according to the baseline risk group. The Student $t$-test or non-parametric Mann-Whitney $U$-test was used to compare means and chi-square test or Fisher exact test to compare proportions. We computed the OR and 95\% CI using logistic regression analysis. Variables with $P<0.1$ in the univariate analysis and known risk factors associated with metachronous neoplasia, such as male sex, ${ }^{15}$ large adenoma, ${ }^{16}$ and multiple adenoma ${ }^{16,17}$ were added to the multivariate logistic regression model to identify risk factors of metachronous neoplasia. All $P$-values were two-tailed. A $P$-value $<0.05$ was considered statistically significant. Statistical analyses were performed using the SPSS version 18.0 for Windows (SPSS Inc., Chicago, IL, USA).

\section{RESULTS}

During the study period, 994 patients underwent colonoscopic polypectomies at index colonoscopy; 895 patients were eligible for this study after the exclusion of 99 patients due to ineligibility as determined by our exclusion criteria or insufficient data (Fig. 1). The study group of 895 subjects included 593 men (66.3\%) and 302 women (33.7\%) with a mean age of $57.5 \pm 11.0$ years. Surveillance colonoscopy was performed in 399 patients (44.6\%) after approximately 37 months (36.9 \pm 19.7 months) after complete colonoscopic polypectomies at index colonoscopy. In this retrospective cohort, there was no colonoscopy-related perforation or interval cancer.

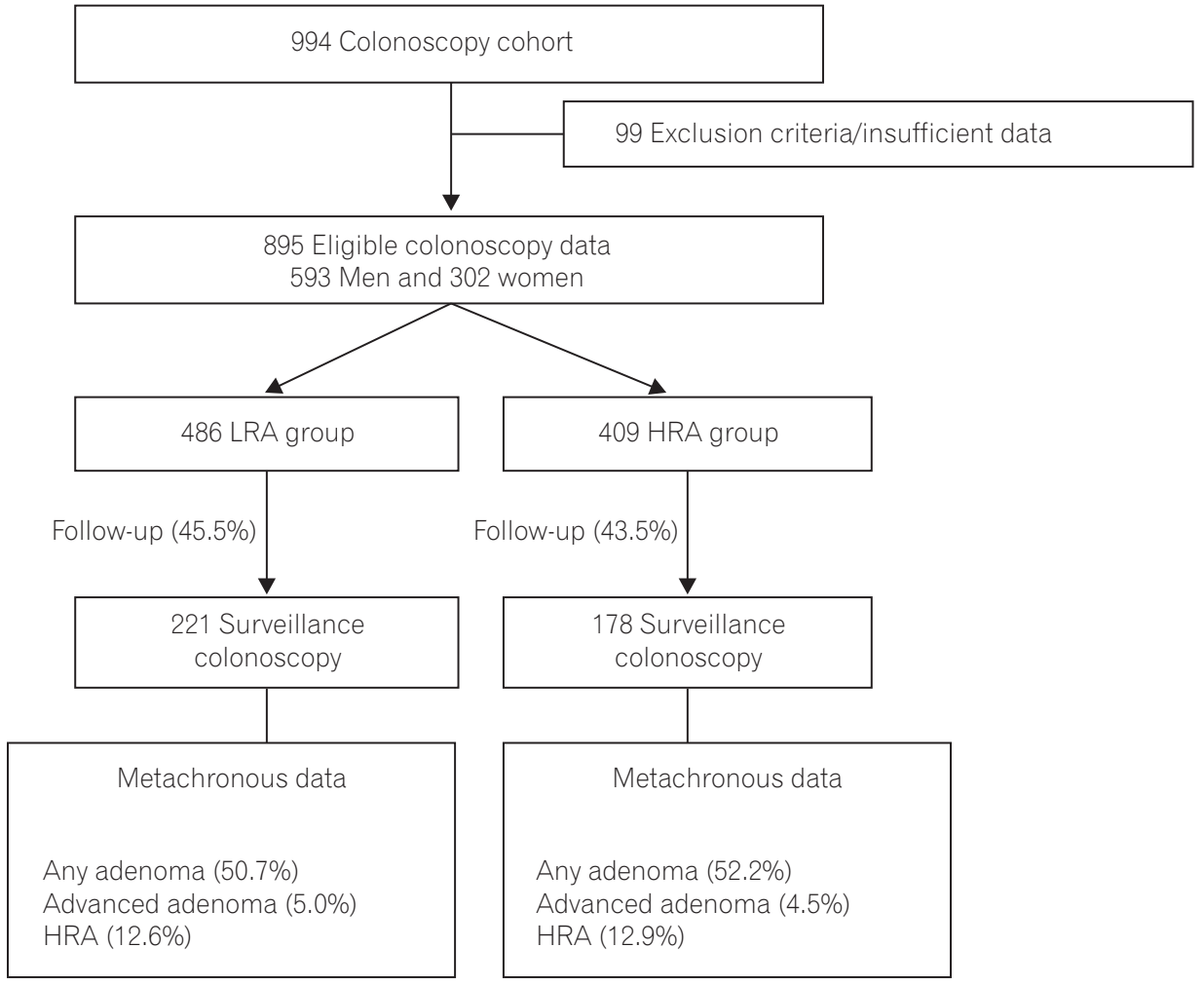

Fig. 1. Overview of the study design. The study included 895 cohort patients who underwent complete colonoscopic polypectomies. After baseline colonoscopic polypectomy, patients underwent one or more surveillance colonoscopies according to risk stratification of index colonoscopy. The rate of surveillance colonoscopy in the low-risk adenoma (LRA) and high-risk adenoma (HRA) groups were $45.5 \%$ and $43.5 \%$, respectively. 


\section{Clinical and Pathological Characteristics of Study Population}

Table 1 shows the clinical and pathological characteristics of study patients at the time of index colonoscopy according to their risk of colorectal neoplasia. Compared with the LRA group, the patients in the HRA group were older and experienced more conscious sedative procedures and procedural complications. In addition, patients with multiple, larger, or advanced adenomas were more frequently included in the HRA group than in the LRA group.

Table 2 shows the clinical and pathological characteristics of study patients at the time of index colonoscopy according to the surveillance colonoscopy. The rate of surveillance colonoscopy in the LRA and HRA groups were similar ( $45.5 \%$ vs. $43.5 \%, P=0.558$ ). In total, the 399 patients who underwent surveillance colonoscopy included 298 men (69.7\%) and 121 women (30.3\%) with a mean age of $56.6 \pm 9.3$ years. In the LRA group, follow-up loss was more frequently noted in female patients, non-smokers, and patients with distal adenomas. In the HRA group, follow-up loss was more frequently noted in elderly patients and those with lower body mass indices and number of adenomas. For patients who underwent surveillance colonoscopy, the clinical characteristics were similar between the LRA and HRA groups.
Table 1. Baseline Characteristics of the Study Population at Index Colonoscopy according to Risk Group

\begin{tabular}{|c|c|c|c|}
\hline Characteristic & $\begin{array}{l}\text { LRA group } \\
\quad(n=486)\end{array}$ & $\begin{array}{l}\text { HRA group } \\
(n=409)\end{array}$ & $P$-value \\
\hline \multicolumn{4}{|l|}{ Clinical characteristics } \\
\hline Age (yr) & $56.3 \pm 11.0$ & $59.0 \pm 10.7$ & $<0.001$ \\
\hline Male sex & $315(64.8)$ & $278(68.0)$ & 0.320 \\
\hline Height (cm) & $164.2 \pm 8.1$ & $165.0 \pm 8.5$ & 0.221 \\
\hline Weight (kg) & $66.3 \pm 10.6$ & $66.6 \pm 11.6$ & 0.700 \\
\hline Smoker & $168(34.6)$ & $165(40.3)$ & 0.075 \\
\hline Family history of CRC & $19(3.9)$ & $19(4.6)$ & 0.586 \\
\hline Aspirin/NSAID user & $53(10.9)$ & $31(7.6)$ & 0.089 \\
\hline \multicolumn{4}{|l|}{ Endoscopic characteristics } \\
\hline Conscious sedation & $347(71.4)$ & $336(82.2)$ & $<0.001$ \\
\hline Procedural complications & $5(1.0)$ & $20(4.9)$ & $<0.001$ \\
\hline Follow-up (yes) & $221(45.5)$ & $178(43.5)$ & 0.558 \\
\hline \multicolumn{4}{|l|}{ Pathological characteristics } \\
\hline Number & $1.3 \pm 0.5$ & $2.5 \pm 1.7$ & $<0.001$ \\
\hline Size $(m m)$ & $5.9 \pm 1.9$ & $11.5 \pm 5.7$ & $<0.001$ \\
\hline Location (proximal) & $235(48.4)$ & $202(49.4)$ & 0.464 \\
\hline Shape (non-polypoid) & $71(14.6)$ & $71(17.4)$ & 0.262 \\
\hline Advanced adenoma & 0 & $337(82.4)$ & $<0.001$ \\
\hline
\end{tabular}

Table 2. Baseline Characteristics of the Study Population at Index Colonoscopy according to Follow-up

\begin{tabular}{|c|c|c|c|c|c|c|}
\hline Characteristic & \multicolumn{3}{|c|}{ LRA group $(n=486)$} & \multicolumn{3}{|c|}{ HRA group $(n=409)$} \\
\hline Age (yr) & $56.1 \pm 9.4$ & $56.5 \pm 12.2$ & 0.649 & $57.3 \pm 9.1$ & $60.4 \pm 9.0$ & 0.003 \\
\hline Male sex & $156(70.6)$ & $159(60.0)$ & 0.015 & $122(68.5)$ & $156(67.5)$ & 0.829 \\
\hline Smoker & $92(41.6)$ & $76(28.7)$ & 0.003 & 78 (43.8) & $97(42.0)$ & 0.208 \\
\hline Family history of CRC & $7(3.2)$ & $12(4.5)$ & 0.441 & $9(5.1)$ & $10(4.3)$ & 0.729 \\
\hline Aspirin/NSAID user & $29(13.1)$ & $24(9.1)$ & 0.152 & $17(9.6)$ & $14(6.1)$ & 0.186 \\
\hline \multicolumn{7}{|c|}{ Pathological characteristics } \\
\hline Shape (non-polypoid) & $31(14.0)$ & $40(15.1)$ & 0.740 & $28(15.7)$ & 43 (18.6) & 0.445 \\
\hline Serrated polyp & $33(14.9)$ & 44 (16.6) & 0.603 & $33(18.5)$ & $44(19.0)$ & 0.896 \\
\hline
\end{tabular}

Values are presented as mean \pm SD or number (\%).

LRA, low-risk adenoma; HRA, high-risk adenoma; CRC, colorectal cancer. 


\section{Risk and Characteristics of Metachronous Neoplasia according to Baseline Risk Group}

The quality of the surveillance colonoscopy was excellent, which was represented by $100.0 \%$ adequate preparation, $100 \%$ cecal intubation rate, and sufficient withdrawal time (11.7 \pm 7.9 minutes). The quality of preparation, cecal intubation rate, and withdrawal time were similar between the LRA and HRA groups. The pathological characteristics of metachronous neoplasia were also similar between the LRA and HRA groups (Table 3 ). As expected, the surveillance interval was significantly longer in the LRA group than in the HRA group $(P=0.001)$. In total, $83.3 \%$ of patients in the LRA group had surveillance colonoscopies within 5 years and $70.2 \%$ of patients in the HRA group had surveillance colonoscopies within 3 years of the index colonoscopy. The 5- and 3-year risk of metachronous advanced adenoma was $3.2 \%$ and $2.3 \%$, respectively, in the LRA group and the 3- and 1-year risk of metachronous advanced adenoma was only $1.7 \%$ and $0.6 \%$, respectively, in the HRA group. There was no significant difference in the risk of metachronous adenoma after 5 or 3 years, regardless of the baseline risk group.

\section{Risk and Characteristics of Metachronous Neoplasia according to Surveillance Interval}

Table 4 shows the pathological characteristics of metachronous neoplasia according to the surveillance interval. In the LRA group, the risk and characteristics of metachronous neoplasia were similar between the surveillance intervals of

Table 3. Risk and Characteristics of Metachronous Neoplasia at Surveillance Colonoscopy according to Risk Group

\begin{tabular}{|c|c|c|c|}
\hline Characteristic & LRA group $(n=221)$ & HRA group $(n=178)$ & $P$-value \\
\hline \multicolumn{4}{|l|}{ Quality of surveillance colonoscopy } \\
\hline Bowel preparation (BBPS score) & $7.7 \pm 0.9$ & $7.6 \pm 0.9$ & 0.427 \\
\hline Adequate preparation (BBPS score $\geq 5$ ) & $221(100.0)$ & $178(100.0)$ & 1.000 \\
\hline Cecal intubation rate & $221(100.0)$ & $178(100.0)$ & 1.000 \\
\hline Withdrawal time (min) & $9.2 \pm 4.1$ & $10.1 \pm 4.6$ & 0.820 \\
\hline \multicolumn{4}{|l|}{ Colonoscopy surveillance interval } \\
\hline Within 1-year & $10(4.5)$ & $21(11.8)$ & 0.007 \\
\hline Within 3-year & $117(52.9)$ & $125(70.2)$ & $<0.001$ \\
\hline Within 5-year & $184(83.3)$ & $159(89.3)$ & 0.083 \\
\hline \multicolumn{4}{|l|}{ Characteristics of metachronous neoplasia } \\
\hline Adenoma & $112(50.7)$ & $93(52.2)$ & 0.755 \\
\hline Advanced adenoma & $11(5.0)$ & $8(4.5)$ & 0.822 \\
\hline HRA & $28(12.6)$ & $23(12.9)$ & 0.940 \\
\hline \multicolumn{4}{|l|}{ Adenoma characteristics } \\
\hline Number & $1.7 \pm 1.2$ & $2.1 \pm 1.8$ & 0.078 \\
\hline Size $(m m)$ & $5.2 \pm 3.3$ & $5.0 \pm 2.7$ & 0.685 \\
\hline Location (proximal) & $59(26.7)$ & $49(27.5)$ & 0.294 \\
\hline \multicolumn{4}{|l|}{ Risk of metachronous adenoma } \\
\hline 1-Year cumulative rate & $6(2.7)$ & $12(6.7)$ & 0.054 \\
\hline 3-Year cumulative rate & $57(25.8)$ & $60(33.7)$ & 0.084 \\
\hline 5-Year cumulative rate & $93(42.1)$ & $81(45.5)$ & 0.493 \\
\hline \multicolumn{4}{|l|}{ Risk of metachronous advanced adenoma } \\
\hline 1-Year cumulative rate & 0 & $1(0.6)$ & 1.000 \\
\hline 3-Year cumulative rate & $5(2.3)$ & $3(1.7)$ & 0.488 \\
\hline 5-Year cumulative rate & $7(3.2)$ & $7(3.9)$ & 0.780 \\
\hline
\end{tabular}

Values are presented as mean \pm SD or number (\%).

LRA, low-risk adenoma; HRA, high-risk adenoma; BBPS, Boston bowel preparation scale. 
$<5$ years and $\geq 5$ years. However, in the HRA group, the risk of metachronous advanced adenoma was slightly higher at the surveillance interval of $\geq 3$ years than at $<3$ years $(9.4 \%$ vs. $2.4 \%, P=0.05)$.

\section{Univariate and Multivariate Analysis Model for Metachronous Advanced Adenoma}

Table 5 shows the univariate and multivariate analysis model for metachronous advanced adenoma. In the uni- variate analysis, the 3-year surveillance interval was significantly associated with metachronous advanced adenoma $(P=0.036)$. To determine the risk factors for metachronous advanced adenoma, we performed logistic regression analysis adjusted for age, male sex, smoking, multiple adenomas, large adenoma, and 3-year surveillance interval. In this analysis, age (OR, 1.062; 95\% CI, 1.008-1.118; $P=0.024)$ and $\geq 3$ year surveillance interval (OR, 2.972; 95\% CI, 1.114-7.928; $P=0.030$ ) were found to be independent risk factors of metachronous advanced adenoma.

Table 4. Pathological Characteristics of Metachronous Neoplasia according to Surveillance Interval in the LRA and HRA Groups

\begin{tabular}{|c|c|c|c|c|c|c|}
\hline \multirow[b]{2}{*}{ Characteristic } & \multicolumn{3}{|c|}{ LRA group } & \multicolumn{3}{|c|}{ HRA group } \\
\hline & $\begin{array}{l}\text { Within } 5 \text { years } \\
\qquad(n=184)\end{array}$ & $\begin{array}{c}5 \text { Years or more } \\
(n=37)\end{array}$ & $P$-value & $\begin{array}{l}\text { Within } 3 \text { years } \\
\qquad(n=125)\end{array}$ & $\begin{array}{c}3 \text { Years or more } \\
(n=53)\end{array}$ & $P$-value \\
\hline Adenoma & $93(50.5)$ & $19(51.4)$ & 0.929 & $60(48.0)$ & $33(62.3)$ & 0.081 \\
\hline Advanced adenoma & $7(3.8)$ & 4 (10.8) & 0.092 & $3(2.4)$ & $5(9.4)$ & 0.052 \\
\hline \multicolumn{7}{|c|}{ Metachronous adenoma characteristics } \\
\hline Number & $1.6 \pm 1.1$ & $2.1 \pm 1.9$ & 0.296 & $2.0 \pm 1.9$ & $2.2 \pm 1.6$ & 0.527 \\
\hline Size (mm) & $5.0 \pm 3.0$ & $5.7 \pm 4.4$ & 0.397 & $4.8 \pm 2.8$ & $5.2 \pm 2.6$ & 0.489 \\
\hline Location (proximal) & $54(58.1)$ & $5(26.3)$ & 0.072 & 35 (58.3) & $14(42.4)$ & 0.295 \\
\hline
\end{tabular}

Values are presented as number (\%) or mean \pm SD.

LRA, low-risk adenoma; HRA, high-risk adenoma.

Table 5. Univariate and Multivariate Analysis Model for Metachronous Advanced Adenoma

\begin{tabular}{|c|c|c|c|c|}
\hline \multirow{2}{*}{ Variable } & \multicolumn{2}{|c|}{ Univariate analysis } & \multicolumn{2}{|c|}{ Multivariate analysis } \\
\hline & OR $(95 \% \mathrm{Cl})$ & $P$-value & OR $(95 \% \mathrm{Cl})$ & $P$-value \\
\hline Age (continuous) & 1.045 (0.995-1.096) & 0.076 & 1.060 (1.007-1.117) & 0.027 \\
\hline Male sex & 0.599 (0.195-1.845) & 0.372 & $0.884(0.227-3.436)$ & 0.859 \\
\hline $\mathrm{BMI}\left(\geq 25 \mathrm{~kg} / \mathrm{m}^{2}\right)$ & $1.391(0.475-4.075)$ & 0.547 & - & - \\
\hline Smoking & 2.409 (0.928-6.254) & 0.071 & 2.969 (0.911-9.672) & 0.071 \\
\hline Family history of CRC & - & 0.999 & - & - \\
\hline Aspirin/NSAID user & $1.469(0.411-5.250)$ & 0.554 & - & - \\
\hline \multicolumn{5}{|c|}{ Pathology at index colonoscopy } \\
\hline Multiple ( $\geq 2$ ) adenomas & 2.051 (0.790-5.324) & 0.140 & $1.963(0.705-5.467)$ & 0.197 \\
\hline Large ( $\geq 10 \mathrm{~mm}$ ) adenoma & $1.501(0.589-3.827)$ & 0.395 & $1.441(0.538-3.860)$ & 0.468 \\
\hline Proximal adenoma & $0.608(0.239-1.545)$ & 0.296 & - & - \\
\hline Non-polypoid adenoma & $1.576(0.504-4.924)$ & 0.434 & - & - \\
\hline \multicolumn{5}{|l|}{ Surveillance interval (yr) } \\
\hline$\geq 3$ & $2.204(0.866-5.607)$ & 0.097 & $2.972(1.114-7.928)$ & 0.030 \\
\hline$\geq 5$ & 2.304 (0.796-6.669) & 0.124 & - & - \\
\hline
\end{tabular}

CRC, colorectal cancer. 


\section{DISCUSSION}

In view of optimal resource distribution, the optimal interval for surveillance colonoscopy is important because the need for surveillance colonoscopy has been dramatically increased as a result of increased use of CRC screening in Korea. ${ }^{18,19}$ Our study showed that $83.3 \%$ of patients in the LRA group had a surveillance colonoscopy within 5 years and $70.2 \%$ of patients in the HRA group had a surveillance colonoscopy within 3 years of their index colonoscopy. The cumulative risk of metachronous advanced adenoma was $3.2 \%$ when surveillance colonoscopy was performed within 5 years of the index colonoscopy in the LRA group and only $1.7 \%$ when performed within 3 years of the index colonoscopy in the HRA group. The risk of metachronous advanced adenoma was similar between the surveillance intervals of $<5$ and $\geq 5$ years in the LRA group. However, it was slightly higher at the surveillance interval of $\geq 3$ than at $<3$ years in the HRA group ( $9.4 \%$ vs. $2.4 \%, P=0.052$ ). In multivariate analysis, age and $\mathrm{a} \geq 3$-year surveillance interval were significant independent risk factors of metachronous advanced adenoma ( $P=0.024$ and $P=0.030$, respectively).

In the present study, most patients had a surveillance colonoscopy before the recommended guidelines, despite having a low risk of metachronous neoplasia. Overutilization of surveillance colonoscopy may lead to unnecessary costs, expose patients to risks associated with unnecessary colonoscopy, and strain the capacity for colonoscopy; ${ }^{20}$ however, overutilization of surveillance colonoscopy has been common in Japan and Korea. ${ }^{7,21-24}$ In a large, prospective study in Korea, $53.5 \%$ of patients in the LRA group had a surveillance colonoscopy within 5 years and $36.6 \%$ of patients in the HRA group had surveillance colonoscopy within 3 years of their index colonoscopy. ${ }^{7}$ In a Korean survey, about $50 \%$ of colonoscopists performed a surveillance colonoscopy after 3 years for patients in the LRA group and more than $60 \%$ of colonoscopists followed up after 1 year in the HRA group. ${ }^{23}$ Another Korean survey also showed that more than $90 \%$ of colonoscopists performed surveillance colonoscopy before guideline recommendations. ${ }^{21}$ In a Japanese survey, about 97\% of LRA responders had a follow-up after 3 years and approximately $44 \%$ to $77 \%$ of HRA responders had a follow-up after 1 year. ${ }^{24}$ In a recent Japanese study, two or more surveillance colonoscopies were reported within 5 years in patients with LRA. ${ }^{22}$ The overutilization of surveillance colonoscopy may be due to the concern about interval colon polyps, ${ }^{24,25}$ lower colonoscopy costs, and lack of confidence in the guidelines. ${ }^{9-11}$ Therefore, further study is required to increase adherence to guideline recommendations for surveillance colonoscopy in clinical practice.

Currently, the post-polypectomy surveillance interval is recommended based on the risk stratifications from the index colonoscopy. Owing to disparities in prevalence and characteristics of colorectal neoplasia, ${ }^{8}$ as well as differences in the health-care systems between the Korean and Western populations, the optimal surveillance interval for the Korean population may be different from that of the West. In the present study, the 5-year cumulative risk of metachronous advanced adenoma was $3.2 \%$ in the LRA group. In a recent Korean prospective cohort study, ${ }^{7}$ the 5 -year cumulative incidence rate of advanced adenoma in patients with LRA was $2.4 \%$. In a randomized controlled trial by Lieberman et al., ${ }^{26}$ the 5 -year cumulative incidence rate of advanced neoplasia after removing LRA was 6.4\%. Therefore, a 5 -year surveillance interval seems to be reasonable for LRA Korean patients. However, in the HRA group, the 3-year cumulative risk of metachronous advanced adenoma was only $1.7 \%$. The 3-year cumulative incidence rate of advanced adenoma after the removal of an advanced adenoma was only $3.8 \%$ in a Chinese study ${ }^{27}$ and $6.8 \%$ in a Japanese study. ${ }^{28} \mathrm{~A}$ lower cumulative incidence rate of advanced adenoma in our study may reflect the exclusion of patient data due to incomplete baseline colonoscopy and the fact that all of our colonoscopies were high-quality. Considering a low 3-year risk of metachronous advanced adenoma for HRA in Asian studies, the optimal interval of surveillance colonoscopy may be tailored to HRA in Asian population., ${ }^{7,27,28}$

Many previous studies ${ }^{15-17}$ evaluated the risk factors of metachronous neoplasia after complete polypectomy; however, the known risk factors were inconsistent. Seo et al. ${ }^{15}$ found that male sex and multiple (three or more) adenomas were independent risk factors for metachronous advanced neoplasia in a large retrospective series. In a retrospective study of 3,360 patients, ${ }^{16}$ the independent risk factors for metachronous neoplasia after removal of advanced adenoma included size, number, and HGD of advanced adenoma. In an old Japanese study, histological findings of carcinoma and multiple neoplasias at index colonoscopy were significant risk factors for metachronous neoplasia. ${ }^{17}$ In the current study, the known risk factors, as well as potential factors by univariate analysis, were included and old age and a surveillance interval of $>3$ years were factors independently associated with metachronous advanced adenoma.

There are several advantages to our study. This is one of the few studies from Asia that reports the risk of metachronous neoplasia after colonoscopic polypectomy according 
to baseline risk stratifications. Our data may represent the real clinical practice for the surveillance colonoscopy in Korea. Furthermore, data collected in this study were of high quality, despite the study's retrospective design. High-quality colonoscopy was reflected by excellent profiles of quality indicators at surveillance colonoscopy. In addition, subjects with poor bowel preparations at their baseline colonoscopy were excluded from data analysis in our study. We concede a few limitations of our study. First, our study is a retrospective, single-center study, which may limit the generalization of our findings. Second, patients with diminutive polyps removed by biopsy only or without adenoma (adenoma-free) were excluded from this study, as our study was focused on the risk of metachronous lesions after complete polypectomy. Finally, many patients in both the LRA and the HRA groups did not undergo surveillance colonoscopy, which could result in selection bias; however, the bias may not be as high because the important clinical characteristics were similar in patients with or without surveillance colonoscopy. These limitations may warrant prospective, multicenter studies on this issue.

In conclusion, most patients had surveillance colonoscopy before the recommended guidelines despite having a low risk of metachronous neoplasia. In addition, the risk of metachronous advanced adenoma was increased in elderly patients and those who had a $\geq 3$-year surveillance interval.

\section{REFERENCES}

1. Levin B, Lieberman DA, McFarland B, et al. Screening and surveillance for the early detection of colorectal cancer and adenomatous polyps, 2008: a joint guideline from the American Cancer Society, the US Multi-Society Task Force on Colorectal Cancer, and the American College of Radiology. Gastroenterology 2008;134:1570-1595.

2. Rex DK, Johnson DA, Anderson JC, et al. American College of Gastroenterology guidelines for colorectal cancer screening 2009. Am J Gastroenterol 2009;104:739-750.

3. Arditi C, Peytremann-Bridevaux I, Burnand B, et al. Appropriateness of colonoscopy in Europe (EPAGE II): screening for colorectal cancer. Endoscopy 2009;41:200-208.

4. Lieberman DA, Rex DK, Winawer SJ, et al. Guidelines for colonoscopy surveillance after screening and polypectomy: a consensus update by the US Multi-Society Task Force on Colorectal Cancer. Gastroenterology 2012;143:844-857.

5. Cairns SR, Scholefield JH, Steele RJ, et al. Guidelines for colorectal cancer screening and surveillance in moderate and high risk groups (update from 2002). Gut 2010;59:666-689.
6. Yang DH, Hong SN, Kim YH, et al. Korean guidelines for postpolypectomy colonoscopy surveillance. Clin Endosc 2012;45:44-61.

7. Chung SJ, Kim YS, Yang SY, et al. Five-year risk for advanced colorectal neoplasia after initial colonoscopy according to the baseline risk stratification: a prospective study in 2452 asymptomatic Koreans. Gut 2011;60:1537-1543.

8. Cha JM, Kozarek RA, La Selva D, et al. Disparities in prevalence, location, and shape characteristics of colorectal neoplasia between South Korean and U.S. patients. Gastrointest Endosc 2015;82:1080-1086.

9. Mysliwiec PA, Brown ML, Klabunde CN, Ransohoff DF. Are physicians doing too much colonoscopy? A national survey of colorectal surveillance after polypectomy. Ann Intern Med 2004;141:264-271.

10. Boolchand V, Olds G, Singh J, Singh P, Chak A, Cooper GS. Colorectal screening after polypectomy: a national survey study of primary care physicians. Ann Intern Med 2006;145:654-659.

11. Saini SD, Kim HM, Schoenfeld P. Incidence of advanced adenomas at surveillance colonoscopy in patients with a personal history of colon adenomas: a meta-analysis and systematic review. Gastrointest Endosc 2006;64:614-626.

12. Calderwood AH, Jacobson BC. Comprehensive validation of the Boston bowel preparation scale. Gastrointest Endosc 2010;72:686-692.

13. Lai EJ, Calderwood AH, Doros G, Fix OK, Jacobson BC. The Boston bowel preparation scale: a valid and reliable instrument for colonoscopy-oriented research. Gastrointest Endosc 2009;69(3 Pt 2):620-655.

14. Hamilton SR, Aaltonen LA. Pathology and genetics of tumours of the digestive system. Lyon: IARC Press, 2000.

15. Seo JY, Chun J, Lee C, et al. Novel risk stratification for recurrence after endoscopic resection of advanced colorectal adenoma. Gastrointest Endosc 2015;81:655-664.

16. Facciorusso A, Di Maso M, Serviddio G, et al. Factors associated with recurrence of advanced colorectal adenoma after endoscopic resection. Clin Gastroenterol Hepatol 2016;14:11481154.el.

17. Fukutomi Y, Moriwaki H, Nagase S, et al. Metachronous colon tumors: risk factors and rationale for the surveillance colonoscopy after initial polypectomy. J Cancer Res Clin Oncol 2002;128:569-574.

18. National health insurance statistical yearbook for 2012. The National Health Insurance Corporation Web site. http://www.nhis. or.kr/bbs7/boards/B0075/5959. Accessed March 9, 2016.

19. Trend of studies about economic evaluation of the cancer screening programs. The National Health Insurance Corporation Web site. http://www.nhic.or.kr. Accessed March 9, 2016. 
20. Patel N, Tong L, Ahn C, Singal AG, Gupta S. Post-polypectomy guideline adherence: importance of belief in guidelines, not guideline knowledge or fear of missed cancer. Dig Dis Sci 2015;60:2937-2945.

21. Kang MS, Park DI, Park JH, et al. A survey on the interval of postpolypectomy surveillance colonoscopy. Korean J Gastrointest Endosc 2006;33:339-345.

22. Kawamura T, Oda Y, Murakami Y, et al. Relationship between frequency of surveillance colonoscopy and colorectal cancer prevention. Dig Endosc 2014;26:409-416.

23. Sohn DK; Colonoscopy Study Group of the Korean Society of Coloproctology. A survey of colonoscopic surveillance after polypectomy. Ann Coloproctol 2014;30:88-92.
24. Tanaka S, Obata D, Chinzei R, et al. Surveillance after colorectal polypectomy: comparison between Japan and U.S. Kobe J Med Sci 2011;56:E204-E213.

26. Lieberman DA, Weiss DG, Harford WV, et al. Five-year colon surveillance after screening colonoscopy. Gastroenterology 2007;133:1077-1085.

27. Huang Y, Gong W, Su B, et al. Recurrence and surveillance of colorectal adenoma after polypectomy in a southern Chinese population. J Gastroenterol 2010;45:838-845.

28. Yamaji Y, Mitsushima T, Ikuma H, et al. Incidence and recurrence rates of colorectal adenomas estimated by annually repeated colonoscopies on asymptomatic Japanese. Gut 2004;53:568-572. 